\title{
Analisis Remaining Life dan Penjadwalan Program Inspeksi pada Pressure Vessel dengan Menggunakan Metode Risk Based Inspection (RBI)
}

\author{
Dyah Arina Wahyu L, Dwi Priyanta dan Dhimas Widhi H. \\ Jurusan Teknik Sistem Perkapalan, Fakultas Teknologi Kelautan, Institut Teknologi Sepuluh Nopember (ITS) \\ Jl. Arief Rahman Hakim, Surabaya 60111 Indonesia \\ e-mail : priyanta@its.ac.id
}

\begin{abstract}
Abstrak-Seiring perkembangan eksplorasi minyak dan gas bumi di dunia, perusahaan minyak dan gas di Indonesia juga turut berlomba-lomba untuk mendapatkan ladang minyak dan gas bumi sebanyak-banyaknya. Perkembangan ini turut dipengaruhi oleh aturan-aturan pemerintah mengenai keselamatan dan pencegahan bahaya baik pada unit yang dikelola maupun tenaga kerja pengelola. Untuk itu semua perlatan-peralatan (unit kerja) harus dijamin kehandalaannya agar tidak menimbulkan bahaya baik bagi pekerja maupun lingkungan. Subjek penelitian dalam tugas akhir ini ialah pada pressure vessel yang dimiliki oleh Terminal LPG Semarang. Kemungkinan bahaya yang dapat menyebabkan kerusakan pada pressure vessel perlu dianalisis agar dapat meminimalkan resiko yang akan terjadi. Metode Risk Based Inspection (RBI) diharapkan dapat meminimalkan resiko yang ada pada pressure vessel. Penilaian resiko dalam tugas akhir ini mengacu pada standar API RP 581. Untuk mengetahui besarnya resiko yang ada pada plant, maka terlebih dahulu harus dihitung besarnya probabilitas kegagalan dan konsekuensi apabila terjadi kegagalan. Langkah selanjutnya ialah membandingkan besarnya resiko yang didapat dengan target resiko yang dimiliki oleh perusahaan. Dari hasil perbandingan ini dapat diketahui tingkat resiko pressure vessel, sehingga dapat ditentukan jadwal inspeksi dan metode inspeksi yang tepat.
\end{abstract}

Kata Kunci-API RP 581, inspeksi, konsekuensi, pressure vessel, probabilitas, resiko, risk based inspection.

\section{PENDAHULUAN}

$\mathrm{S}$ ALAH satu alat penunjang dalam eksplorasi dan eksploitasi minyak dan gas bumi ialah pressure vessel. Pressure vessel didefinisikan sebagai bejana/wadah yang didesain untuk dapat menahan tekanan baik internal maupun eksternal. [1] Terminal LPG Semarang memiliki beberapa unit pressure vessel jenis storage tank. Setiap pressure vessel memiliki umur produksi yang sangat bergantung pada jenis dan penggunaan pressure vessel itu sendiri. Apabila terus dilakukan pengoperasian melebihi umur yang seharusnya, dikhawatirkan dapat mengakibatkan bahaya-bahaya yang tidak diinginkan.

Kemungkinan bahaya yang dapat menyebabkan kerusakan pada pressure vessel perlu dianalisis agar dapat meminimalkan resiko yang akan terjadi. Identifikasi bahaya tersebut harus dapat mewakili semua potensi bahaya yang berpengaruh terhadap kinerja pressure vessel. Sehingga, setelah diperhitungkan analisis resiko dan langkah mitigasinya, perlu di pertimbangkan pula jadwal dan metode inspeksi. Hal ini dilakukan agar kinerja pressure vessel dapat maksimal sehingga akan didapatkan hasil produksi yang sebaikbaiknya.[2]

Risk based inspection (RBI) adalah suatu metode pendekatan secara modern yang dapat digunakan sebagai tools inspeksi terhadap peralatan berdasarkan kemungkinankemungkinan resiko yang dapat terjadi baik dari segi failure, cost, environtment, safety, dan juga operasi. Diharapkan dengan menggunakan RBI dapat memberikan hasil perhitungan yang akurat terhadap resiko pada pressure vessel sehingga dapat dilakukan upaya-upaya pengendalian yang memadai untuk mencegah terjadinya kegagalan. [3]

Proses penilaian resiko dilakukan untuk mengidentifikasi seluruh kemungkinan yang mungkin dapat membahayakan kesehatan manusia, lingkungan, proses produksi, maupun peralatan. Langkah awal dari risk assessment adalah identifikasi bahaya dan dampak dari bahaya tersebut. Siapa saja dan apa saja yang akan terkena dampak dari bahaya tersebut. [4]

Metode RBI mendefinisikan tingkat resiko peralatan yang dianalisis sebagai kombinasi dari dua parameter yaitu peluang kegagalan dan konsekuensi kegagalan. Analisis peluang kegagalan berhubungan dengan besar kecilnya peluang sebuah peralatan mengalami kegagalan. Sedangkan analisis konsekuensi kegagalan berhubungan dengan dampak yang dihasilkan dari kejadian kegagalan. [5]

\section{METODOLOGI PENELITIAN}

Studi yang dilakukan adalah bertujuan untuk mengetahui tingkat resiko pada pressure vessel. Tingkat resiko dapat diketahui dengan menghitung besarnya resiko yang dimiliki oleh peralatan, kemudian membandingkannya dengan target resiko. Dari perbandingan ini dapat diketahui tingkat resiko yang ada, apakah dibawah risk target atau telah melebihi risk target.

Penilaian resiko dilakukan dengan mengombinasikan besarnya peluang kegagalan dan konsekuensi kegagalan. Sehingga langkah awal dalam studi RBI ini ialah menghitung besarnya probabilitas kegagalan. Probabilitas kegagalan sangat dipengaruhi oleh penyebab kegagalan. API 581 memberikan 21 penyebab kegagalan. Penentuan penyebab kegagalan dilakukan dengan screening kriteria seperti yang 
diberikan oleh API 581.

Langkah selanjutnya setelah didapatkan probabilitas kegagalan ialah menghitung besarnya konsekuensi kegagalan. Konsekuensi kegagalan dipengaruhi oleh ukuran lubang pelepasan, laju pelepasan atau massa pelepasan, sistem deteksi dan isolasi, dll.

Setelah probabilitas dan konsekuensi kegagalan didapat, maka dapat dihitung besarnya resiko pada saat dilakukan RBI. Besarnya resiko yang ada selanjutnya dibandingkan dengan risk target, dan dilakukan penilaian RBI. Penilaian RBI dilakukan untuk mengetahui jadwal inspeksi dan metode inspeksi yang tepat untuk pressure vessel.

\section{ANALISIS DATA DAN PEMBAHASAN}

\section{A. Probabilitas Kegagalan}

Probabilitas kegagalan dihitung menggunakan persamaan 1 berikut ini :

PoF $=$ gff $x$ FMS $\times$ DF

Dimana :

PoF : Probabilitas kegagalan

gff : generic failure frequency

$\mathrm{F}_{\mathrm{MS}}$ : factor management systems

DF : damage factor

Nilai gff menyatakan besarnya frekuensi kegagalan pada masing-masing peralatan. Nilai generic failure frequency diberikan oleh API 581. Sedangkan FMS menunjukan faktor sistem manajemen yang dimiliki oleh perusahaan. Penentuan nilai factor management system dilakukan oleh pihak perusahaan. Penilaian tersebut berdasarkan daftar pertanyaanpertanyaan seperti pada Annex 2B API 581.

Damage factor merupakan faktor yang paling mempengaruhi penyebab kegagalan peralatan. Penentuan damage factor dilakukan dengan melakukan screening seperti yang diberikan oleh API 581. Hasil damage factor untuk pressure vessel ialah thinning damage factor dan external damage factor (multiple damage factor). Sedangkan damage factor untuk piping systems ialah mechanical fatigue.

Perhitungan damage factor pada pressure vessel dipengaruhi oleh kategori keefektivitasan inspeksi yang telah dilakukan. Inspeksi yang telah dilakukan ialah 2 kali dengan metode inspeksi visual examination dengan pengukuran ketebalan. Kategori efektivitas inspeksi menentukan parameter damage factor. Sehingga besarnya damage factor dapat ditentukan berdasarkan tabel 5.1 API 581.

Perhitungan damage factor untuk piping system dipengaruhi oleh kondisi sistem perpipaan. Kondisi tersebut meliputi kejadian kegagalan pada sistem perpipaan, getaran yang terjadi sistem perpipaan, modifikasi yang pernah dilakukan pada sistem perpipaan, fittings pada sistem perpipaan, dll.

Ringkasan hasil perhitungan probabilitas pressure vessel kegagalan dapat dilihat pada Lampiran A. Sedangkan ringkasan probabilitas piping system dapat dilihat pada Lampiran B.

\section{B. Konsekuensi kegagalan}

Konsekuensi kegagalan dihitung dengan menggunakan persamaan 2 berikut ini :

$C A=\max \left[C A_{\text {cmd }}, C A_{\text {inj }}\right]$

Dimana :

$C A_{\text {cmd }}=$ Konsekuensi area component damage $\left(\mathrm{ft}^{2}\right)$

$C A_{\text {inj }}=$ Konsekuensi area personel injury $\left(\mathrm{ft}^{2}\right)$

Besarnya konsekuensi area component damage dihitung dengan menggunakan persamaan 3 berikut ini :

$C A_{\text {cmd }}=\max \left[C A_{\text {cmd }}^{\text {flam }}, C A_{c m d}^{\text {tox }}, C A_{c m d}^{\text {nfnt }}\right]$

Dimana :

$C A_{\text {cmd }}^{\text {flam }}=$ Konsekuensi area flammable/explosion $\left(\mathrm{ft}^{2}\right)$

$C A_{\text {cmd }}^{\text {tox }}=$ Konsekuensi area toxic $\left(\mathrm{ft}^{2}\right)$

$C A_{\text {cmd }}^{n f n t}=$ Konsekuensi area non-toxic non-flammable $\left(\mathrm{ft}^{2}\right)$

Sedangkan konsekuensi area personel injury dapat dihitung dengan menggunakan persamaan 4 di bawah ini :

$C A_{\text {inj }}=\max \left[C A_{\text {inj }}^{\text {flam }}, C A_{\text {inj }}^{\text {tox }}, C A_{\text {inj }}^{\text {nfnt }}\right]$

Dimana :

$C A_{\text {inj }}^{\text {flam }}=$ Konsekuensi area flammable/explosion $\left(\mathrm{ft}^{2}\right)$

$C A_{i n j}^{\text {tox }}=$ Konsekuensi area toxic $\left(\mathrm{ft}^{2}\right)$

$C A_{\text {inj }}^{n f n t}=$ Konsekuensi area non-toxic non-flammable $\left(\mathrm{ft}^{2}\right)$

API 581 secara umum memberikan 2 kategori konsekuensi, yakni konsekuensi area component damage dan personel injury. Konsekuensi area sangat dipengaruhi oleh massa fluida dan ukuran lubang pelepasan. Analisi konsekuensi dilakukan pada masing-masing ukuran lubang pelepasan. API 581 memberikan 4 ukuran lubang untuk pressure vessel yaitu $1 / 4$ inch, 1 inch, 4 inch, dan 16 inch.

Langkah perhitungan konsekuensi untuk pressure vessel dan piping system ialah sama. Perbedaan hanya terletak pada ukuran lubang yang dianalisis. Untuk pipa, API 581 memberikan ukuran lubang pelepasan mulai $1 / 4$ inch sampai dengan ukuran diameter pipa tersebut. Misal untuk pipa 2", maka ukuran lubang pelepasannya ialah $1 / 4$ inch, 1 inch, dan 2 inch (rupture).

Ringkasan perhitungan konsekuensi area untuk pressure vessel dapat dilihat pada lampiran C. Sedangkan tabel 1 dibawah ini menunjukkan hasil akhir konsekuensi area pada sistem perpipaan.

Table 1 konsekuensi area pada piping system

\begin{tabular}{lcc}
\hline \hline No. & Peralatan & Konsekuensi $\left(\mathrm{ft}^{2}\right)$ \\
\hline 1. & Pipa 2“ tangki V110 & 2387.885 \\
2. & Pipa 2“ tangki V110 & 2387.885 \\
3. & Pipa 2“ tangki V110 & 2387.885 \\
4. & Pipa 2“ tangki V110 & 2387.885 \\
5. & Pipa 4“ tangki V110 & 69040.89 \\
6. & Pipa 4“ tangki V110 & 69040.89 \\
7. & Pipa 4“ tangki V110 & 69040.89 \\
8. & Pipa 4“ tangki V110 & 69040.89 \\
\hline \hline
\end{tabular}

\section{Penilaian Resiko}

Resiko dihitung pada kondisi RBI date dan Plan date. Besarnya resiko dihitung dengan menggunakan persamaan 5 di bawah ini :

$$
\text { Risk }=\text { PoF } \times \text { CoF }
$$


Dimana :

PoF : Probabilitas Kegagalan

CoF : Konsekuensi kegagalan

Tingkat resiko pada pressure vessel dapat diketahui dengan membandingkan hasil perhitungan resiko pada RBI date dan Plan date dengan besarnya risk target. Maka dari itu resiko dihitung dengan rumusan 5 diatas.

Tabel 2 di bawah ini menunjukkan besarnya resiko pada masing-masing pressure vessel.

\begin{tabular}{lccc}
\multicolumn{4}{c}{ Tabel 2. Resiko pada Masing-masing Pressure Vessel } \\
\hline \hline No. & Equipment & Pada RBI date & Pada Plan date \\
\hline 1. & PoF PV-110 & 17.732 & 65.0195 \\
2. & PoF PV-120 & 17.732 & 65.0195 \\
3. & PoF PV-130 & 17.732 & 65.0195 \\
4. & PoF PV-140 & 17.732 & 65.0195 \\
\hline \hline
\end{tabular}

Penentuan resiko untuk piping system dibatasi cukup pada risk matrix. Risk matrix merupakan kombinasi antara kategori probabilitas dengan kategori konsekuensi. Tabel 3 berikut ini menampilkan kategori probilitas kegagalan dan konsekuensi kegagalan.

Tabel 3. Kategori Resiko

\begin{tabular}{|c|c|c|c|}
\hline \multicolumn{2}{|c|}{ "Probability Category (1) } & \multicolumn{2}{|c|}{ "Consequence Category (2) } \\
\hline Category & Range & Category & Range $\left(f t^{2}\right)$ \\
\hline 1 & $D f \leq 2$ & $A$ & $C A \leq 100$ \\
\hline 2 & $2<D f \leq 20$ & $B$ & $100<C A \leq 1000$ \\
\hline 3 & $20<D f \leq 100$ & C & $1000<C A \leq 3000$ \\
\hline 4 & $100<D f \leq 1000$ & $D$ & $3000<C A \leq 10000$ \\
\hline 5 & $D f>1000$ & E & $C A>10000$ \\
\hline
\end{tabular}

Sedangkan tabel 8 berikut ini menunjukkan kategori resiko pada piping system.

\begin{tabular}{|c|c|c|}
\hline No. & Equipment & Risk Category \\
\hline 1. & Pipe 2" & $1 C$ \\
\hline 2. & Pipe 4" & $1 E$ \\
\hline
\end{tabular}

\section{Risk Based Inspection (RBI)}

Penilaian RBI dilakukan dengan membandingkan besarnya resiko pada saat $R B I$ date dan plan date dengan besarnya risk target. Gambar 1 dibawah ini menunjukkan tingkat resiko pressure vessel.

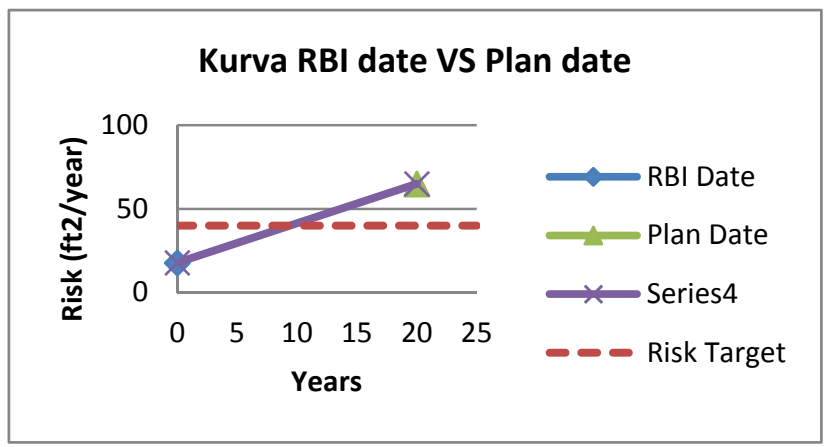

Gambar 1. Grafik Perbandingan RBI date dan Plan date

Titik perpotongan antara resiko dengan risk target menunjukkan waktu inspeksi yang akan dilakukan. Inspeksi dilakukan bertujuan untuk meminimalkan resiko.

Jadwal (waktu) inspeksi dihitung dengan cara menarik garis dari perpotongan resiko dengan risk target. Tabel 9 berikut ini menunjukkan waktu inspeksi pada masing-masing pressure vessel.

Tabel 5. Waktu Inspeksi pada Masing-masing Pressure Vessel

\begin{tabular}{lcc}
\hline \hline No. & Equipment & Waktu (years) \\
\hline 1. & $P V-110$ & 9.42 \\
2. & $P V-120$ & 9.42 \\
3. & $P V-130$ & 9.42 \\
4. & $P V-140$ & 9.42 \\
\hline \hline
\end{tabular}

Besarnya resiko setelah dilakukan inspeksi dihitung dengan mengombinasikan probabilitas kegagalan yang baru dengan konsekuensi kegagalan peralatan. Tabel 10 di bawah ini menunjukkan besarnya resiko pada masing-masing pressure vessel setelah dilakukan inspeksi.

Tabel 6. Besarnya resiko pada masing-masing pressure vessel setelah dilakukan inspeksi

\begin{tabular}{lll}
\hline \hline No. & Equipment & Risk \\
\hline 1. & $P V-110$ & 14.77 \\
2. & $P V-120$ & 14.77 \\
3. & $P V-130$ & 14.77 \\
4. & $P V-140$ & 14.77 \\
\hline \hline
\end{tabular}

\section{E. Kategori Resiko pada Piping Systems}

Tingkat resiko pada piping sistem ditentukan dari risk matrix seperti yang diberikan dalam API 581. Sebelumnya, harus ditentukan terlebih dahulu kategori resiko dengan mengombinasikan probabilitas kegagalan dengan konsekuensi kegagalan. Gambar 2 berikut ini menunjukkan tingkat resiko pressure vessel.
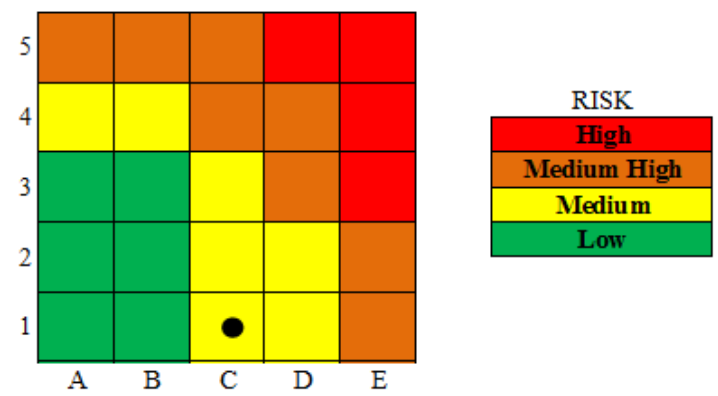

Gambar 2. Risk Matrix of Piping System

Kategori tingkat resiko untuk pipa 2 inch berada pada kategori medium. Sedangkan tingkat resiko pada 4 inch berada pada kategori medium high. Dibutuhkan suatu mitigasi agar dapat meminimalkan resiko yang ada.

\section{KESIMPULAN}

Kesimpulan dari studi RBI ini ialah :

1. Besarnya resiko pada pressure vessel V110, V120, V130, dan V140 adalah $17.732 \mathrm{ft} 2$. Besarnya resiko pada masing-masing pressure vessel adalah sama, hal ini dikarenakan data pada masing-masing pressure vessel sama. 
2. Inspection planning untuk pressure vessel V110, V120, V130, dan V140 diestimasikan pada tahun ke-9 setelah dilakukan analisis RBI, yaitu pada tanggal 22 Juni 2025.

3. Umur sisa (remaining life) pressure vessel V110, V120, V130, dan V140 yaitu 11,1 tahun.

4. Jadwal dan metode inspeksi untuk pengoperasian selama 20 tahun, yaitu :

a. Metode inspeksi

Metode inspeksi yang diharapkan dapat diaplikasikan yaitu UT thickness.

b. Jadwal inspeksi

Jadwal inspeksi berdasarkan analisis RBI ialah pada 22 Juni 2025. Hasil tersebut lebih lama dibandingkan ketentuan SKPP Migas, yaitu setiap 3 tahun sekali. Perbedaan jadwal inspeksi tersebut dapat disebabkan oleh data yang kurang lengkap.

\section{UCAPAN TERIMA KASIH}

Penulis mengucapkan terima kasih kepada bapak Ir. Dwi Pritanta, M.SE dan DR. Dhimas Widhi H., ST., M.Sc selaku dosen pembimbing yang telah memberikan masukan selama pengerjaan tugas akhir ini. Penulis juga mengucapkan terima kasih kepada seluruh karyawan/i Terminal LPG Semarang yang telah membantu baik selama pengambilan data maupun selama pengerjaan studi ini.

\section{DAFTAR PUSTAKA}

[1] American Petroleum Institute (API). 2006. Pressure Vessel Inspection Codes API 510 Ninth Edition. Washington, D.C: API Publishing Services.

[2] Kharismawati, Intan. 2012. Peniaian Resiko dan Perencanaan Program Inspeksi pada Pressure Vessel dengan Menggunakan Metode Risk Based Inspection. Surabaya : ITS.

[3] Zaidun, Yasin. 2010. Analisa Perbandingan Metode Assessment Berbasis Resiko dengan Metode Assessment Berbasis Waktu pada Stasiun Pengolahan Gas. Jakarta : UI.

[4] Muhlbauer, WK. 2004. Pipeline Risk Management Manual, 3rd Edition. Elsevier Inc.

LAMPIRAN A

Ringkasan Perhitungan : Probabilitas Kegagalan

\begin{tabular}{|c|c|c|c|}
\hline \multicolumn{4}{|c|}{ Equipment Type : Pressure Vessel } \\
\hline \multicolumn{4}{|c|}{ Equipment No. $\quad: P V-110$} \\
\hline \multicolumn{4}{|c|}{ Probability of Failure } \\
\hline 1. & Multiple Damage Factor & \multicolumn{2}{|c|}{ Yes / } \\
\hline 2. & Type of Damage Factor & Thinning DF & External DF \\
\hline 3. & Number of Inspection & 2 & 2 \\
\hline 4. & Category of Inspection & $\begin{array}{l}C \text { (fairly } \\
\text { effective) }\end{array}$ & $\begin{array}{l}D \text { (poorly } \\
\text { effective) }\end{array}$ \\
\hline 5. & RBI Date & $22-02-2016$ & $22-06-2016$ \\
\hline 6. & Plan Date & $22-02-2036$ & $22-02-2036$ \\
\hline 7. & Age at RBI Date & 6.5 years & 6.5 years \\
\hline 8. & Age at Plan Date & 26.5 years & 26.5 years \\
\hline 9. & Thickness at last inspection & $58.7(\mathrm{~mm})$ & $58.7(\mathrm{~mm})$ \\
\hline 10. & Age of Coating Inst. & Omitted & 12.5 years \\
\hline 11. & Time-in Service & Omitted & 6.5 years \\
\hline 12. & Base Corrosion Rate & Omitted & $0.127 \mathrm{~mm} / \mathrm{yrs}$ \\
\hline 13. & Corrosion Rate & $0.54 \mathrm{~mm} / \mathrm{yrs}$ & $0.127 \mathrm{~mm} / \mathrm{yrs}$ \\
\hline 14. & Thickness Minimum & $53.725 \mathrm{~mm}$ & $53.725 \mathrm{~mm}$ \\
\hline 15. & Art damage factor at $R B I$ & 0.00 & 0.00 \\
\hline
\end{tabular}

\begin{tabular}{|c|c|c|c|c|}
\hline 16. & $\begin{array}{l}\text { Date } \\
\text { Art damage factor at Plan } \\
\text { Date }\end{array}$ & 0.13 & & 0.12 \\
\hline 17. & DF at RBI Date & 5 & & 1 \\
\hline 18. & DF at Plan Date & 20 & & 2 \\
\hline 19. & Total DF at RBI Date & & 6 & \\
\hline 20. & Total DF at Plan Date & & 22 & \\
\hline 21. & $\begin{array}{l}\text { Total Generic Failure } \\
\text { Frequency (gff) }\end{array}$ & & $3.06 E-05$ & \\
\hline 22. & $\begin{array}{l}\text { Factor Management } \\
\text { System }\left(F_{S M}\right)\end{array}$ & & 0.779 & \\
\hline 23. & $\begin{array}{l}\text { Probability of Failure at } \\
\text { RBI Date }\end{array}$ & & 0.000143 & \\
\hline 24. & $\begin{array}{l}\text { Probability of Failure at } \\
\text { Plan Date }\end{array}$ & & 0.000524 & \\
\hline
\end{tabular}

\section{LAMPIRAN B}

Ringkasan Perhitungan : Konsekuensi Kegagalan

\begin{tabular}{|l|l|c|c|}
\hline \multicolumn{4}{|c|}{ Equipment Type : Piping System at PV-V110 } \\
\hline 1. & Diameter of Pipe & 2 ” & 4 ” \\
\hline 2. & $\begin{array}{l}\text { Base Damage Factor for } \\
\text { Pipeline Failure }\end{array}$ & 50 & 1 \\
\hline 3. & $\begin{array}{l}\text { Base Damage Factor for } \\
\text { Audible Shaking }\end{array}$ & 500 & 500 \\
\hline 4. & $\begin{array}{l}\text { Adjustment Factor for } \\
\text { Audible Shaking }\end{array}$ & 1 & 1 \\
\hline 5. & Cyclic Loading Type & 50 & 50 \\
\hline 6. & $\begin{array}{l}\text { Base Damage Factor for } \\
\text { Piping }\end{array}$ & 500 & 500 \\
\hline 7. & $\begin{array}{l}\text { Adjustment for } \\
\text { Corrective Action }\end{array}$ & 1 & 1 \\
\hline 8. & $\begin{array}{l}\text { Adjustment for Pipe } \\
\text { Complexity }\end{array}$ & 0.002 & 0.002 \\
\hline 9. & $\begin{array}{l}\text { Adjustment for } \\
\text { Condition of Pipe }\end{array}$ & 1 & 1 \\
\hline 10. & $\begin{array}{l}\text { Adjustment for Joint } \\
\text { Type or Branch Design }\end{array}$ & 2 & 2 \\
\hline 11. & $\begin{array}{l}\text { Adjustment for Branch } \\
\text { Diameter }\end{array}$ & 0.02 & 0.02 \\
\hline 12. & Final Damage Factor & 0.04 & 0.04 \\
\hline
\end{tabular}

\section{LAMPIRAN C}

Ringkasan Perhitungan : Konsekuensi Kegagalan

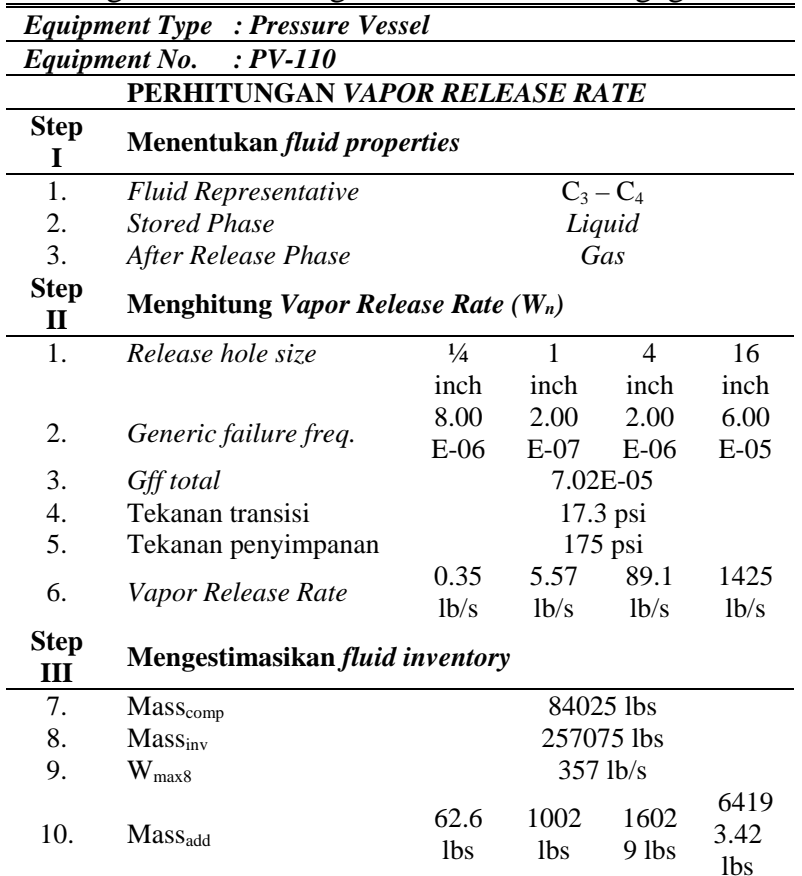




\begin{tabular}{|c|c|c|c|c|c|}
\hline $\begin{array}{c}\text { Step } \\
\text { IV }\end{array}$ & Menentukan Tipe Pelep & $\begin{array}{c}8408 \\
7.61 \\
\text { lbs } \\
\text { asan }\end{array}$ & $\begin{array}{c}8502 \\
6.82 \\
\text { lbs }\end{array}$ & $\begin{array}{l}1000 \\
54.2 \\
1 \mathrm{lbs}\end{array}$ & $\begin{array}{c}1482 \\
18.4 \\
\mathrm{lbs}\end{array}$ \\
\hline 13. & Waktu pelepasan & $\begin{array}{c}2874 \\
7.51 \\
\text { scnd } \\
\text { Cont } \\
\text { inuo } \\
\text { us }\end{array}$ & $\begin{array}{c}1796 \\
.71 \\
\text { scnd } \\
\text { Insta } \\
\text { ntan } \\
\text { eous }\end{array}$ & $\begin{array}{c}112 . \\
29 \\
\text { scnd } \\
\text { Insta } \\
\text { ntan } \\
\text { eous }\end{array}$ & $\begin{array}{c}7.01 \\
8 \\
\text { scnd } \\
\text { Insta } \\
\text { ntan } \\
\text { eous }\end{array}$ \\
\hline $\begin{array}{c}\text { Step } \\
\text { V }\end{array}$ & \multicolumn{5}{|c|}{ Menentukan Dampak Sistem Deteksi dan Isolasi } \\
\hline $\begin{array}{l}14 . \\
15 .\end{array}$ & $\begin{array}{l}\text { Kategori sistem deteksi } \\
\text { Kategori sistem isolasi }\end{array}$ & \multicolumn{4}{|c|}{$\begin{array}{l}\text { B } \\
\text { B }\end{array}$} \\
\hline 16. & $\begin{array}{l}\text { Reduction factor } \\
\text { (fact di) }\end{array}$ & \multicolumn{4}{|c|}{0.15} \\
\hline 17. & Leak duration $\left(I d_{\max }\right)$ & $\begin{array}{c}40 \\
\text { mnts }\end{array}$ & $\begin{array}{c}30 \\
\text { mnts }\end{array}$ & $\begin{array}{c}20 \\
\text { mnts }\end{array}$ & N/A \\
\hline $\begin{array}{c}\text { Step } \\
\text { VI }\end{array}$ & \multicolumn{5}{|c|}{ Menentukan Laju Pelepasan atau Massa Pelepasan } \\
\hline 18. & Laju pelepasan (rate) & $\begin{array}{r}0.3 \\
\mathrm{lb} / \mathrm{s}\end{array}$ & $\begin{array}{l}\text { Omit } \\
\text { ted }\end{array}$ & $\begin{array}{l}\text { Omit } \\
\text { ted }\end{array}$ & Omit \\
\hline 19. & Masa pelepasan (mass) & $\begin{array}{c}\text { Omit } \\
\text { ted }\end{array}$ & $\begin{array}{l}8515 \\
.52 \\
\text { lbs }\end{array}$ & $\begin{array}{c}9083 \\
2.21 \\
\text { lbs }\end{array}$ & $\begin{array}{c}1482 \\
18.4 \\
\text { lbs }\end{array}$ \\
\hline $\begin{array}{l}\text { Step } \\
\text { VII }\end{array}$ & \multicolumn{5}{|c|}{ Menghitung Konsekuensi Area Flammable/Explosion } \\
\hline 20. & $\begin{array}{l}\text { Reduction factor } \\
\left(\text { fact }_{m i}\right)\end{array}$ & & 0 & 2 & \\
\hline 21. & $\begin{array}{l}\text { Energy efficiency } \\
\text { factor } \\
\text { Auto-ignition Not }\end{array}$ & $\begin{array}{l}\text { Omit } \\
\text { ted }\end{array}$ & 0.72 & 4.83 & 5.68 \\
\hline 22. & $\begin{array}{l}\text { Likely Continouos } \\
\text { Release Component } \\
\text { Damage }\end{array}$ & $\begin{array}{c}11.7 \\
\mathrm{ft}^{2}\end{array}$ & $\begin{array}{l}\text { Omit } \\
\text { ted }\end{array}$ & $\begin{array}{c}\text { Omit } \\
\text { ted }\end{array}$ & $\begin{array}{c}\text { Omit } \\
\text { ted }\end{array}$ \\
\hline 23. & $\begin{array}{l}\text { Auto-ignition Likely } \\
\text { Continuous Release } \\
\text { Component Damage }\end{array}$ & $\begin{array}{c}74.2 \\
\mathrm{ft}^{2}\end{array}$ & $\begin{array}{l}\text { Omit } \\
\text { ted }\end{array}$ & $\begin{array}{c}\text { Omit } \\
\text { ted }\end{array}$ & $\begin{array}{c}\text { Omit } \\
\text { ted }\end{array}$ \\
\hline 24. & $\begin{array}{l}\text { Auto-ignition Not } \\
\text { Likely Instantaneous } \\
\text { Release Component } \\
\text { Damage }\end{array}$ & $\begin{array}{l}\text { Omit } \\
\text { ted }\end{array}$ & $\begin{array}{c}2096 \\
7.01 \\
\mathrm{ft}^{2}\end{array}$ & $\begin{array}{c}1719 \\
2.8 \\
\mathrm{ft}^{2}\end{array}$ & $\begin{array}{c}2079 \\
9.48 \\
\mathrm{ft}^{2}\end{array}$ \\
\hline 25. & $\begin{array}{l}\text { Auto-ignition Likely, } \\
\text { Instantaneous Release } \\
\text { Component Damage } \\
\text { Auto-ignition Not }\end{array}$ & $\begin{array}{l}\text { Omit } \\
\text { ted }\end{array}$ & $\begin{array}{c}1736 \\
60.1 \\
\mathrm{ft}^{2}\end{array}$ & $\begin{array}{l}1150 \\
76.4 \\
9 \mathrm{ft}^{2}\end{array}$ & $\begin{array}{c}1332 \\
14.9 \\
\mathrm{ft}^{2}\end{array}$ \\
\hline 26. & $\begin{array}{l}\text { Likely Continouos } \\
\text { Release Personel } \\
\text { Injury }\end{array}$ & $\begin{array}{c}29.6 \\
\mathrm{ft}^{2}\end{array}$ & $\begin{array}{l}\text { Omit } \\
\text { ted }\end{array}$ & $\begin{array}{c}\text { Omit } \\
\text { ted }\end{array}$ & $\begin{array}{c}\text { Omit } \\
\text { ted }\end{array}$ \\
\hline 27. & $\begin{array}{l}\text { Auto-ignition Likely } \\
\text { Continuous Release } \\
\text { Personel Injury }\end{array}$ & $\begin{array}{c}198 \\
\mathrm{ft}^{2}\end{array}$ & $\begin{array}{l}\text { Omit } \\
\text { ted }\end{array}$ & $\begin{array}{c}\text { Omit } \\
\text { ted }\end{array}$ & $\begin{array}{c}\text { Omit } \\
\text { ted }\end{array}$ \\
\hline 28. & $\begin{array}{l}\text { Auto-ignition Not } \\
\text { Likely Instantaneous } \\
\text { Release Personel } \\
\text { Injury }\end{array}$ & $\begin{array}{l}\text { Omit } \\
\text { ted }\end{array}$ & $\begin{array}{c}5678 \\
4.91 \\
\mathrm{ft}^{2}\end{array}$ & $\begin{array}{c}4998 \\
9.99 \\
\mathrm{ft}^{2}\end{array}$ & $\begin{array}{c}6137 \\
1.78 \\
\mathrm{ft}^{2}\end{array}$ \\
\hline 29. & $\begin{array}{l}\text { Auto-ignition Likely, } \\
\text { Instantaneous Release } \\
\text { Personel Injury }\end{array}$ & $\begin{array}{l}\text { Omit } \\
\text { ted }\end{array}$ & $\begin{array}{c}5875 \\
01.7 \\
\mathrm{ft}^{2}\end{array}$ & $\begin{array}{l}3893 \\
10.2 \\
1 \mathrm{ft}^{2}\end{array}$ & $\begin{array}{c}4056 \\
0.61 \\
\mathrm{ft}^{2}\end{array}$ \\
\hline 30. & Blending factor & $\begin{array}{c}0.00 \\
55\end{array}$ & 1 & 1 & 1 \\
\hline 31. & AIT blending factor & & 1736 & & \\
\hline 32. & $\begin{array}{l}\text { Auto-ignition Likely } \\
\text { Component Damage }\end{array}$ & $\begin{array}{c}73.8 \\
\mathrm{ft}^{2}\end{array}$ & $\begin{array}{c}1736 \\
60.0 \\
\mathrm{ft}^{2}\end{array}$ & $\begin{array}{l}1150 \\
76.4 \\
9 \mathrm{ft}^{2}\end{array}$ & $\begin{array}{c}1332 \\
14.9 \\
\mathrm{ft}^{2}\end{array}$ \\
\hline 33. & $\begin{array}{l}\text { Auto-ignition Likely } \\
\text { Personel Injury }\end{array}$ & $\begin{array}{l}197 \\
\mathrm{ft}^{2}\end{array}$ & $\begin{array}{c}5875 \\
01.7 \\
\mathrm{ft}^{2}\end{array}$ & $\begin{array}{l}3893 \\
10.2 \\
1 \mathrm{ft}^{2}\end{array}$ & $\begin{array}{c}4506 \\
73.5 \\
\mathrm{ft}^{2}\end{array}$ \\
\hline 34. & $\begin{array}{l}\text { Auto-ignition Not } \\
\text { Likely Component } \\
\text { Damage }\end{array}$ & $\begin{array}{c}11.6 \\
\mathrm{ft}^{2}\end{array}$ & $\begin{array}{c}2096 \\
7.05 \\
\mathrm{ft}^{2}\end{array}$ & $\begin{array}{l}1719 \\
2.80 \\
4 \mathrm{ft}^{2}\end{array}$ & $\begin{array}{c}2079 \\
9.48 \\
\mathrm{ft}^{2}\end{array}$ \\
\hline 35. & Auto-ignition Not & 29.5 & 5678 & 4998 & 6137 \\
\hline
\end{tabular}

\begin{tabular}{|c|c|c|c|c|c|}
\hline & Likely Personel Injury & $\mathrm{ft}^{2}$ & $\begin{array}{c}4.91 \\
\mathrm{ft}^{2}\end{array}$ & $\begin{array}{c}9.92 \\
\mathrm{ft}^{2}\end{array}$ & $\begin{array}{c}1.78 \\
\mathrm{ft}^{2}\end{array}$ \\
\hline & AIT blended & & 2096 & 1719 & 2079 \\
\hline 36. & $\begin{array}{l}\text { Consequence Area for } \\
\text { Component Damage }\end{array}$ & $\begin{array}{c}11.6 \\
\mathrm{ft}^{2}\end{array}$ & $\begin{array}{c}7.05 \\
\mathrm{ft}^{2}\end{array}$ & $\begin{array}{l}2.8 \\
\mathrm{ft}^{2}\end{array}$ & $\begin{array}{c}9.48 \\
\mathrm{ft}^{2}\end{array}$ \\
\hline & AIT blended & & 5678 & 4998 & 6137 \\
\hline 37. & $\begin{array}{l}\text { Consequence Area for } \\
\text { Personel Injury }\end{array}$ & $\begin{array}{c}29.5 \\
\mathrm{ft}^{2}\end{array}$ & $\begin{array}{c}4.91 \\
\mathrm{ft}^{2}\end{array}$ & $\begin{array}{c}9.92 \\
\mathrm{ft}^{2}\end{array}$ & $\begin{array}{c}1.78 \\
\mathrm{ft}^{2}\end{array}$ \\
\hline & Final Consequence & & \multirow{2}{*}{\multicolumn{3}{|c|}{$42047.097 \mathrm{ft}^{2}$}} \\
\hline 38. & $\begin{array}{l}\text { Area for Component } \\
\text { Damage }\end{array}$ & & & & \\
\hline 39. & $\begin{array}{l}\text { Final Consequence } \\
\text { Area for Personel } \\
\text { Injury }\end{array}$ & & \multicolumn{3}{|c|}{$123983.004 \mathrm{ft}^{2}$} \\
\hline 40. & Consequence Area & & \multicolumn{3}{|c|}{$123983.004 \mathrm{ft}^{2}$} \\
\hline
\end{tabular}

